\title{
Risk Balancing of Cold Ischemic Time against Night Shift Surgery Possibly Reduces Rates of Reoperation and Perioperative Graft Loss
}

\author{
Nikos Emmanouilidis, ${ }^{1}$ Julius Boeckler, ${ }^{1}$ Bastian P. Ringe, ${ }^{1}$ Alexander Kaltenborn, ${ }^{2,3}$ \\ Frank Lehner, ${ }^{1}$ Hans Friedrich Koch, ${ }^{2}$ Jürgen Klempnauer, ${ }^{1}$ and Harald Schrem ${ }^{1,2}$ \\ ${ }^{1}$ General, Visceral and Transplant Surgery, Hannover Medical School, Hannover, Germany \\ ${ }^{2}$ Core Facility Quality Management \& Health Technology Assessment in Transplantation, \\ Integrated Research and Treatment Center Transplantation (IFB-Tx), Hannover Medical School, Hannover, Germany \\ ${ }^{3}$ Trauma and Orthopedic Surgery, Federal Armed Forces Hospital, Westerstede, Germany
}

Correspondence should be addressed to Nikos Emmanouilidis; emmanouilidis.nikos@mh-hannover.de

Received 9 September 2016; Accepted 4 December 2016; Published 19 January 2017

Academic Editor: Simon C. Robson

Copyright (C) 2017 Nikos Emmanouilidis et al. This is an open access article distributed under the Creative Commons Attribution License, which permits unrestricted use, distribution, and reproduction in any medium, provided the original work is properly cited.

Background. This retrospective cohort study evaluates the advantages of risk balancing between prolonged cold ischemic time (CIT) and late night surgery. Methods. 1262 deceased donor kidney transplantations were analyzed. Multivariable regression was used to determine odds ratios (ORs) for reoperation, graft loss, delayed graft function (DGF), and discharge on dialysis. CIT was categorized according to a forward stepwise pattern $\leq 1 h />1 h, \leq 2 h />2 h, \leq 3 h />3 h, \ldots, \leq n h />n h$. ORs for DGF were plotted against CIT and a nonlinear regression function with best $R^{2}$ was identified. First and second derivative were then implemented into the curvature formula $k(x)=f^{\prime \prime}(x) /\left(1+f^{\prime}(x)^{2}\right)^{3 / 2}$ to determine the point of highest CIT-mediated risk acceleration. Results. Surgery between $3 \mathrm{AM}$ and $6 \mathrm{AM}$ is an independent risk factor for reoperation and graft loss, whereas prolonged CIT is only relevant for DGF. CIT-mediated risk for DGF follows an exponential pattern $f(x)=A \cdot\left(1+k \cdot e^{(I \cdot x)}\right)$ with a cut-off for the highest risk increment at 23.5 hours. Conclusions. The risk of surgery at 3 AM-6 AM outweighs prolonged CIT when confined within 23.5 hours as determined by a new mathematical approach to calculate turning points of nonlinear time related risks. CIT is only relevant for the endpoint of DGF but had no impact on discharge on dialysis, reoperation, or graft loss.

\section{Introduction}

The standard procedure of kidney transplantation is a retroperitoneal graft-placement into the right or left iliac fossa with vascular end-to-side anastomosis of the donor artery to the recipient's iliac artery, an anastomosis of the donor vein to the recipient's iliac vein or vena cava, and a connection of the donor ureter to the recipient's bladder. The applied technique for ureter-to-bladder anastomosis [1-4] and the mode of vascular anastomosis (e.g., with or without aortic or venous patch) depend on the relations of the donorto-recipient ureter/bladder anatomy and donor-to-recipient vascular three-dimensional geometry [5-9].
It is known that perioperative success or failure in kidney transplantation is related to donor organ quality [10-12], recipient comorbidities [13], quality of surgery [14, 15], and immunological parameters $[16,17]$ and that each of these categories contains hazards that can lead to one of the three major adverse events: (1) reoperation, (2) delayed graft function, or (3) graft loss. Furthermore, it is accepted that most of these hazards are unchangeable and elusive of control by the transplant surgeon at the time of scheduled surgery.

Nevertheless, there are two significant and time related hazards, cold ischemic time and night shift surgery, which are connected and sensitive to the timing of surgery. Therefore, it seems comprehensible that the transplanting surgeon might 
want to balance between these two variables, if CIT and night shift surgery would emerge as diametrically related hazards for the outcome of kidney transplantations.

\section{Patients and Methods}

2.1. Study Population. This is a single-center retrospective database analysis of all $N=1786$ adult kidney transplantations performed between 1 January 2000 and 31 October 2013 at Hannover Medical School. All kidney transplants were performed after cold storage and a conventional cold perfusion during the organ harvest procedure using HTK preservation solution (Histidine-Tryptophan-Ketoglutarate, Custodiol ${ }^{\circledR}$ HTK, Dr. Franz Köhler Chemie GmbH, 64625 Bensheim, Germany). Machine perfusion techniques were not applied.

2.2. Inclusion and Exclusion Criteria. All consecutive standard kidney transplants defined as implantation of primary deceased single donor kidney transplantations into a pristine iliac fossa of an adult recipient (age $>18$ years) were included. Living related transplantations, kidney retransplantations, and transplantations of organs with variant anatomy, such as double ureter or horseshoe kidneys, were excluded. Kidney transplants with synchronous procedures such as lung, heart, liver, or pancreas transplantation, ileum conduit, ureter-toureter anastomosis, nephrectomy, dialysis catheter removal, appendectomy, cholecystectomy, or inguinal hernia repair were excluded as well. After applying these inclusion and exclusion criteria a total number of $n=1262$ patients with standard kidney transplants remained for analyses.

2.3. Data Collection. Data was collected on donor organs, recipients, surgery, and adverse events (Tables 1-6 and Supplemental Table in Supplementary Material available online at https://doi.org/10.1155/2017/5362704). Reasons for graft nephrectomy were discriminated into surgery related and nonsurgical causes by evaluation of the operative reports, clinical charts, and the pathological reports from the removed kidney transplants.

2.4. Study Endpoints. The investigated study endpoints were delayed graft function [Yes/No], defined as temporary postoperative dialysis with dialysis-free hospital discharge, hospital discharge on dialysis [Yes/No], early postoperative graft loss [Yes/No], postoperative graft loss due to surgical reasons [Yes/No], and reoperation [Yes/No] during the initial hospital stay.

2.5. Definition of Time Intervals for Day-and Nighttime Surgery. For the analysis of a possible risk development during day- or nighttime surgery the circadian 24 hours was analyzed using different permutations of defined time intervals with the goal of identifying time blocks of day- and nighttime surgery that are associated with the most significant risk increments for the investigated study endpoints. The starttimes of surgery (skin incision times) determined the day or night shift intervals each kidney transplantation was assigned to.
2.6. Surgeons and Operative Procedures. Deceased donor kidney transplants were performed on 24 hours a day, seven days a week basis by a team of either two or three or seldom four surgeons. All ureter-to-bladder anastomoses were performed using the Gregoir-Lich antireflux technique [1]. Donor arteries were anastomosed end-to-side to the recipient's iliac artery. Performance of the operation with or without aortic patch as well as the choice of the exact anatomic site for anastomoses varied from case to case according to the individual vascular geometry of the recipient's and donor kidney's arteries. The same principle was applied for venous anastomoses to the iliac vein or vena cava.

2.7. Shift Regulations for Surgeons and Surgical Staff. Regular working hours at our institution are from 07:30 AM to 4:30 PM with a 30 minutes' rest-time. Surgeons and staff who are assigned for night shift will start working at 07:30 am and they have the same workload during the day as any other surgeons or staff members, who are not assigned for night shift. Night shift surgery then starts at 04:30 PM and ends at 07:30 AM the next morning (Figure 1(a)). Thus, surgeons or staff members who are assigned for night shifts do have an overall work-time of 24 hours (Figure 1(b)). After a continuous 24-hour shift all surgeons and staff are obliged to have $24 \mathrm{~h}$ off-time by law and will not start working again until the next morning. During night shifts there are no elective procedures. The night shift team consists of 3 surgeons: one senior surgeon, one senior resident, and one junior resident. Further, the night shift team also includes two examined scrub nurses. Surgeons, scrub nurses, and anesthesiologists are assigned randomly to night shifts without regard to upcoming kidney transplantations.

2.8. Surgical Experience and Teaching. A surgeons' experience with kidney transplantation was estimated by the number of performed transplants he accumulated until the date of each transplant (labeled here as CUSUM). This measure of surgical experience was examined for significant differences in distribution between investigated time intervals. Teaching transplants were defined as operations performed by a primary surgeon with less surgical seniority as compared to the assisting surgeon.

\subsection{Statistical Analyses}

2.9.1. Missing Data. Patterns of missing data were analyzed by Little's test for Missing Data Completely at Random (MCAR) using SPSS Version 22 (PASW Statistics Inc., IBM, Somers, NY, USA). Missing data had a verified MCAR pattern, if significance level was $p>0.05$.

2.9.2. Uni- and Multivariable Regression Analysis. Binary univariable regression analysis was used to determine the odds ratios and the significance level of risk factors for the investigated study endpoints. Risk factors with significant $p$ values $<0.05$ as well as purposefully selected risk factors with $p$ values $<0.200$ were chosen for inclusion into risk-adjusted multivariable regression after exclusion of multicollinearity with the goal of determining significant independent risk 


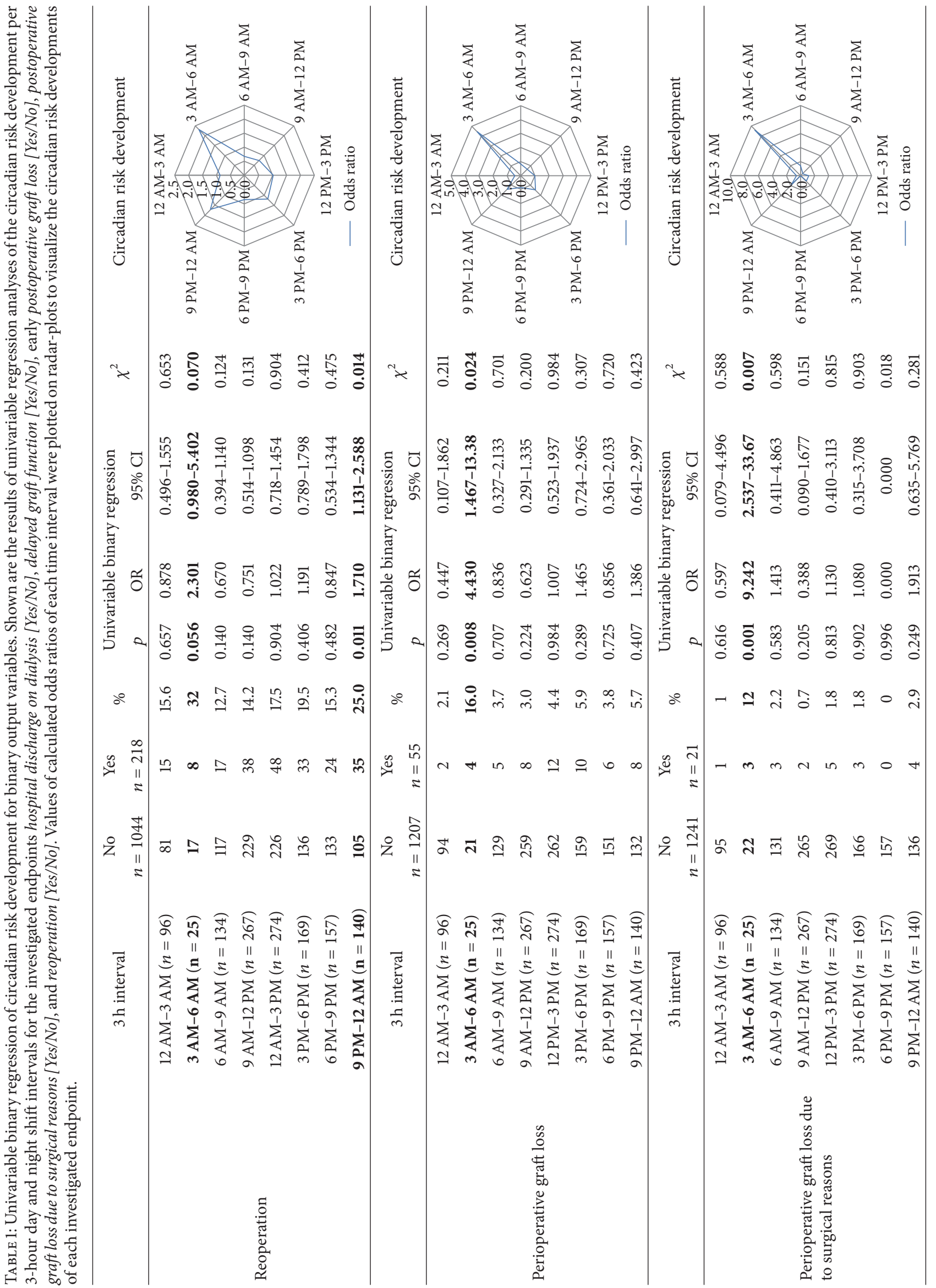




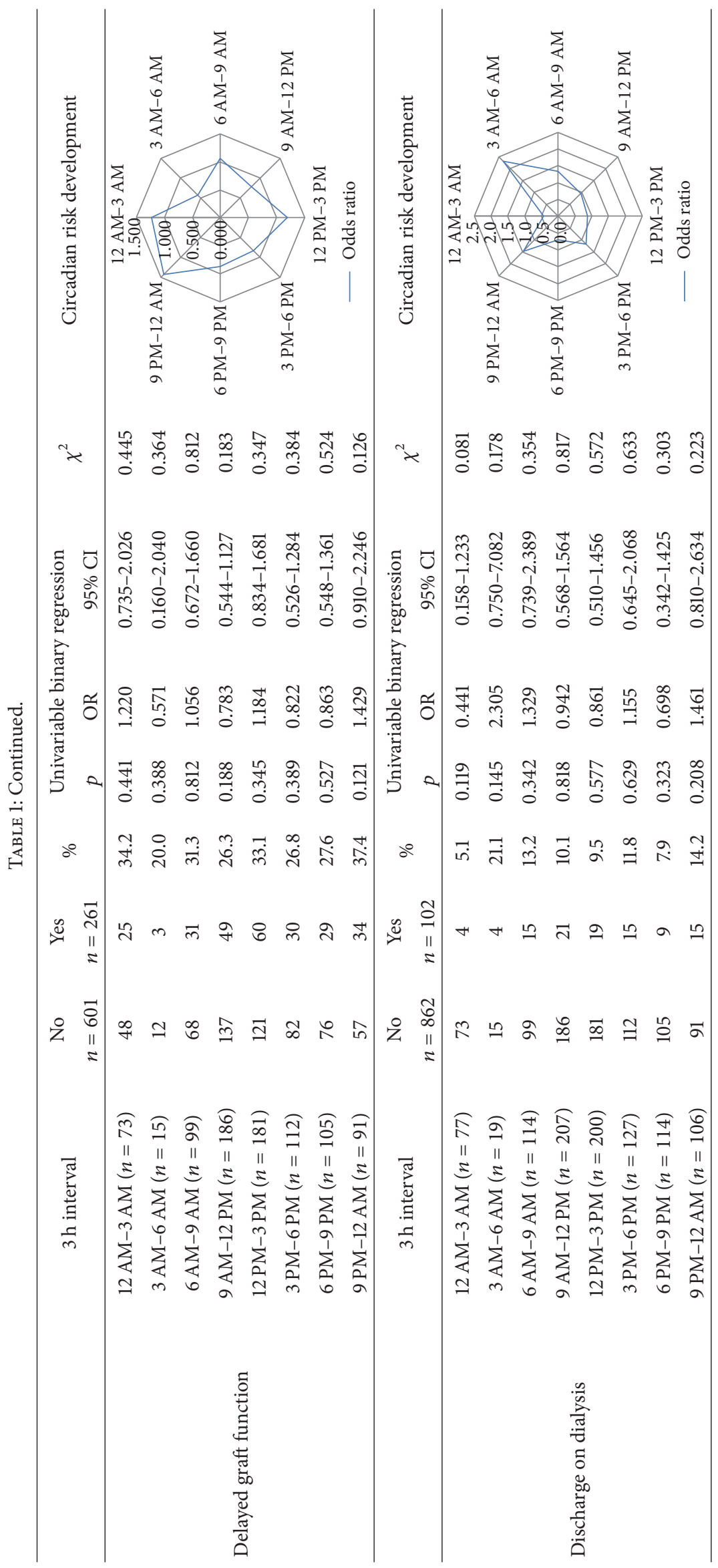




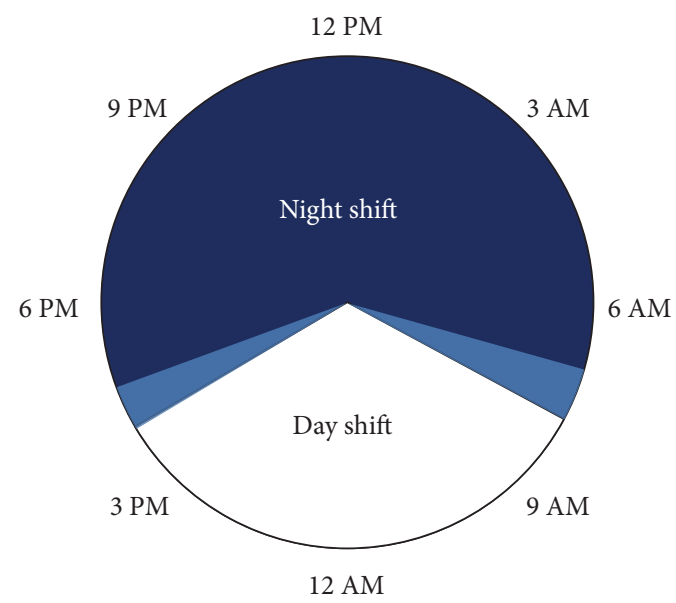

(a)

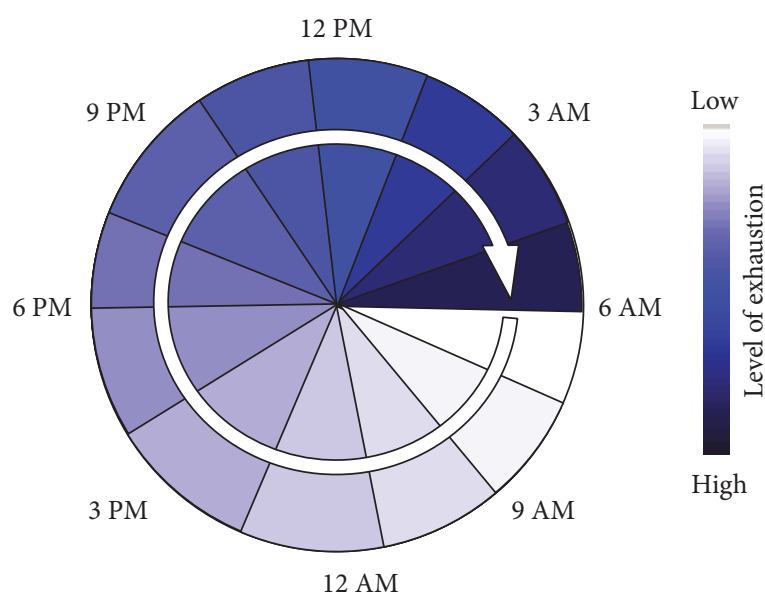

(b)

FIGURE 1: (a) Shown is the distribution of night- and daytime shifts over 24 hours at our institution. Regular working hours at our institution are 07:30 AM to 4:30 PM. Included are two hand-over periods of 30-45 minutes for each shift change (light blue sectors). Only in cases of high urgent emergencies (e.g., bowl perforations, intraabdominal bleeding, and polytrauma situations) would surgery be started within those intervals. If arrival of an upcoming kidney transplantation is scheduled after $6 \mathrm{AM}$, the transplantation is usually planned to start with the day shift team after 7:30 AM. (b) This circle with the increasing dyeing of the sectors symbolizes the increasing levels of exhaustion that can be caused by sleep deprivation and a continuous workload over the course of a 24 -hour shift.

TABLE 2: Proportions of teaching operations and distribution of the cumulative sum (CUSUM) of the 1st surgeons' kidney transplantations over the $3 \mathrm{~h}$ time intervals. Shown are the distribution of teaching operations and the distribution of the cumulative sum (CUSUM) of the 1st surgeons' kidney transplantations over the $3 \mathrm{~h}$ time intervals. There was no significant difference in distribution of CUSUM between the 3 hour intervals (Levene's test, $p=0.627$ ) (Supplemental Figure $\mathrm{b}$ ). The proportion of teaching operations was unequally distributed between the 9 PM and 12 AM time interval and the two time intervals of 6 AM-9 AM and 9 AM-12 PM, with a significant higher proportion of teaching operations during the morning shift hours between $6 \mathrm{AM}$ and $12 \mathrm{PM}\left(\mathrm{Chi}^{2}\right.$ test $\left.p<0.05\right)$ (Supplemental Figure a). The proportion of teaching operations within the 3 AM-6 AM interval was not significantly different compared to all other 3-hour intervals $\left(\mathrm{Chi}^{2}\right.$ test $\left.p>0.05\right)$.

\begin{tabular}{|c|c|c|c|c|c|c|c|c|c|}
\hline \multirow{2}{*}{$3 \mathrm{~h}$ time interval } & \multicolumn{4}{|c|}{ Teaching operation } & \multicolumn{5}{|c|}{ CUSUM } \\
\hline & Expected $(n)$ & Counted $(n)$ & $\%$ & $95 \% \mathrm{CI}$ & Mean & Max & Min & Med & SD \\
\hline $12 \mathrm{AM}-3 \mathrm{AM}(n=96)$ & 65 & 62 & 65 & $54.16 ; 74.08$ & 54.5 & 345 & 1 & 37.5 & 52.3 \\
\hline $3 \mathrm{AM}-6 \mathrm{AM}(n=25)$ & 17 & 17 & 68 & $46.50 ; 85.05$ & 56.8 & 235 & 4 & 39.0 & 52.0 \\
\hline $6 \mathrm{AM}-9 \mathrm{AM}(n=134)$ & 90 & 103 & 77 & $68.80 ; 83.71$ & 52.9 & 341 & 1 & 29.5 & 60.1 \\
\hline $9 \mathrm{AM}-12 \mathrm{PM}(n=267)$ & 180 & 194 & 73 & $66.89 ; 77.91$ & 45.0 & 330 & 1 & 29.0 & 55.5 \\
\hline $12 \mathrm{PM}-3 \mathrm{PM}(n=274)$ & 185 & 191 & 70 & $63.89 ; 75.09$ & 39.6 & 361 & 1 & 22.0 & 51.9 \\
\hline 3 PM-6 PM $(n=169)$ & 114 & 112 & 66 & $58.61 ; 73.35$ & 39.7 & 350 & 1 & 26.0 & 46.5 \\
\hline 6 PM-9 PM $(n=157)$ & 106 & 96 & 61 & $53.05 ; 68.81$ & 49.8 & 347 & 1 & 33.0 & 51.9 \\
\hline $9 \mathrm{PM}-12 \mathrm{AM}(n=140)$ & 94 & 76 & 54 & $45.66 ; 62.72$ & 50.9 & 346 & 1 & 38.0 & 54.5 \\
\hline
\end{tabular}

factors for the study endpoints. $p$ values $<0.05$ were defined as significant. $\mathrm{Chi}^{2}$ tests and Levene's tests were performed with Minitab 17 (Minitab Inc., State College, Pennsylvania, USA). Univariable and multivariable regression statistics were performed with SPSS Version 22 (PASW Statistics Inc., IBM, Somers, NY, USA).

2.9.3. Conversion of the Continuous Variable of Cold Ischemic Time to a Categorical Variable and Modelling of a Nonlinear Regression Function of the CIT Dependent Risk for Delayed Graft Function. As a result of the multivariable regression analysis of the investigated study endpoints we found that cold ischemic time (CIT) was only relevant for the study endpoint of delayed graft function (DGF) (see Results). In order to investigate the relationship of CIT with the binary endpoint of $D G F$ [Yes/No] we calculated the risk increments for DGF as odds ratios (OR) for each additional hour of cold ischemic time (CIT). In order to do so we categorized the continuous variable CIT in a stepwise forward fashion according to the pattern $\leq 1 h />1 h, \leq 2 h />2 h, \leq 3 h />3 h, \ldots, \leq n h />n h$, and so forth. The calculated ORs for each hour of CIT progression were then graphically plotted as a function of OR by CIT to visualize the pattern of risk development over time. The approach of an hourly stepwise forward calculation of risk increments and the avoidance of the traditional technique of linear regression modelling enabled circumventing the otherwise determined (analysis inherent) result of a linear correlation between DGF risk and CIT. Thus, neither a nonlinear function nor a linear function of DGF by CIT was excluded from the beginning. Contrary to the traditional 
TABLE 3: Regression analysis of the risks for reoperation $(n=218)$. Shown are the results of univariable and multivariable binary regression analyses to determine the odds ratios of the investigated variables for the risk of reoperation $(n=218)$ during primary hospitalization. Analyzed were all 1262 standard kidney transplants into nonpreoperated sites performed between 1 January 2000 and 31 October 2013. Included into risk-adjusted multivariable analyses were those variables with a $p$ value $<0.2$ in univariable regression analyses.

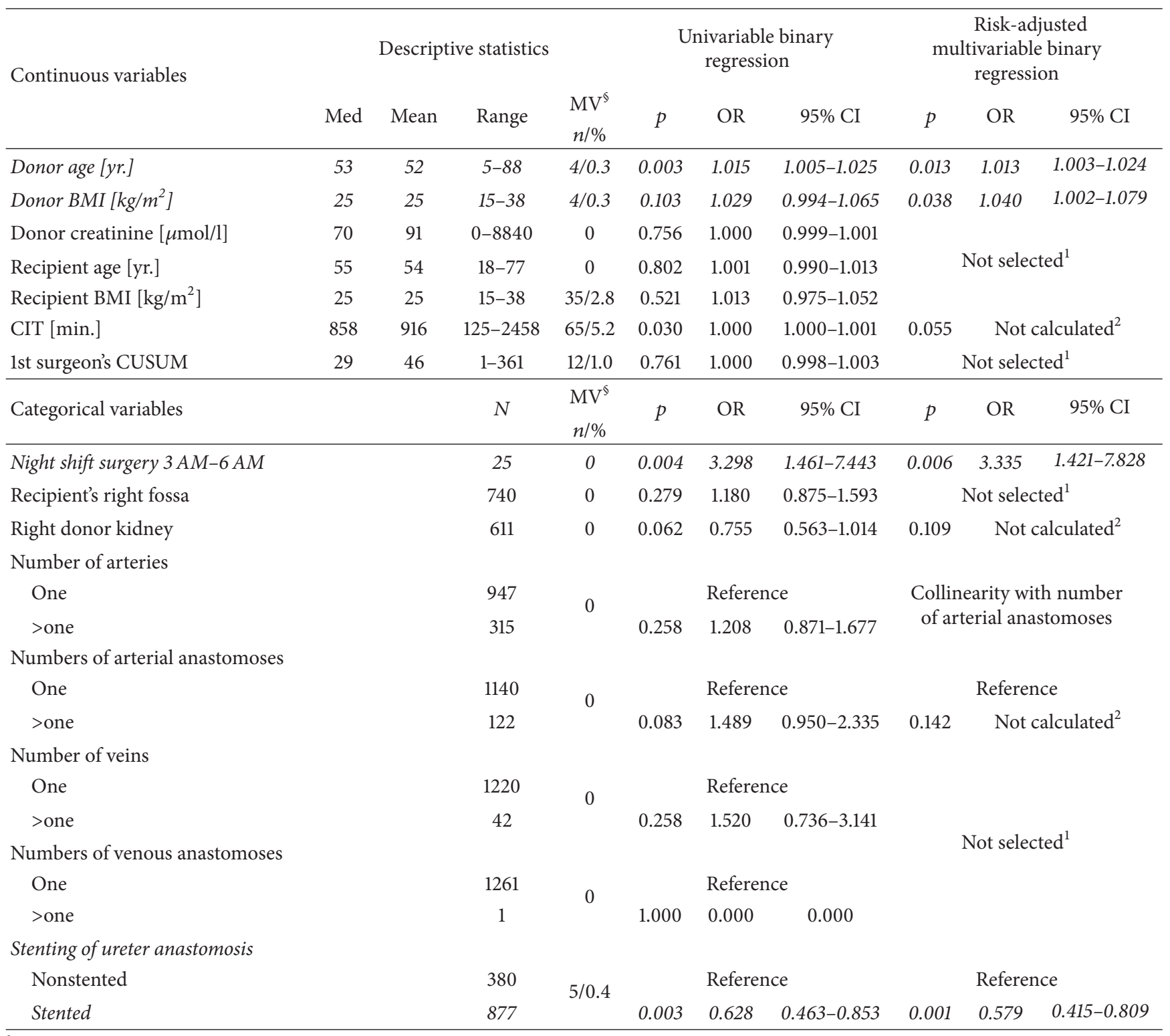

${ }^{1}$ Not selected for multivariable regression because of a $p$ value $>0.2$ in univariable analyses.

${ }^{2}$ Odds ratios and $95 \%$ CI were not calculated because of a $p$ value $>0.05$ in multivariable analyses.

${ }^{\S}$ Little's MCAR test: Chi-Square $=31.909, \mathrm{DF}=33$, and $p=0.521$.

approach of an intentional choice of the analysis method we let the plotted data guide our choice for a rightful regression modelling to find a mathematical function with best estimated fit (lowest SSE and best $R^{2}$ ).

Using JMP ${ }^{\circledR}$ Pro Version 11.2.0 (SAS Institute Inc., Cary, NC, USA) we finally identified a nonlinear regression function of the type $f(x)=A *\left(1+k \cdot e^{(I \cdot x)}\right)(A=$ asymptotic, $k=$ scale, and $I=$ increment) with lowest SSE and best $R^{2}$ (Figure 2(a)).

First and second derivate of that function were implemented to the two-dimensional curvature formula [27] $k(x)=$ $f^{\prime \prime}(x) /\left(1+f^{\prime}(x)^{2}\right)^{3 / 2}$. The first derivate of the curvature formula with $k^{\prime}(x)=0$ was then used to calculate the point of highest acceleration in risk development and defined as CIT cut-off for risk balancing (Figure 2(b)).

\section{Results}

3.1. Missing Data. Missing value (MV) analysis by Little's MCAR verified a pattern of data completely missing at random with $p$ values ranging from 0.434 to 0.795 (Tables 3, 4, 


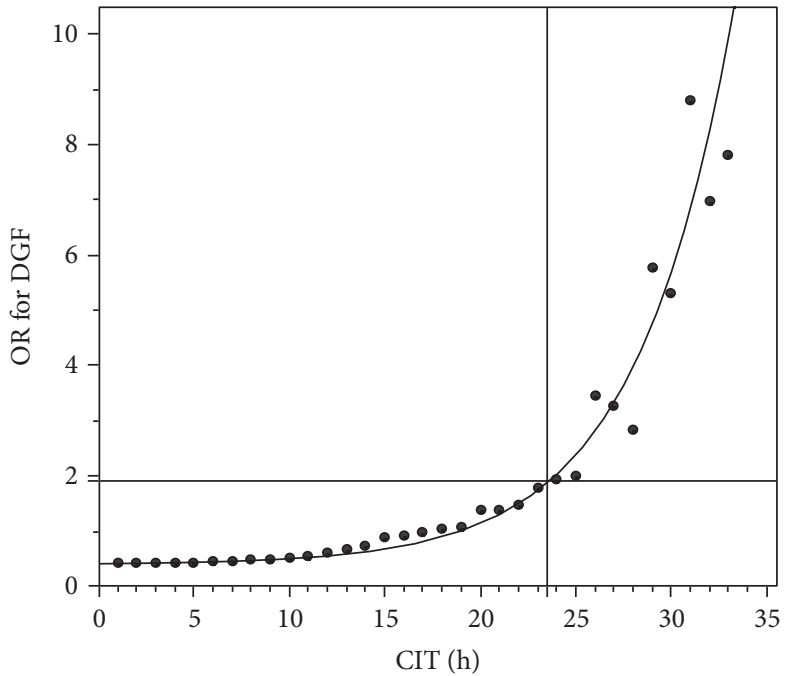

(a)

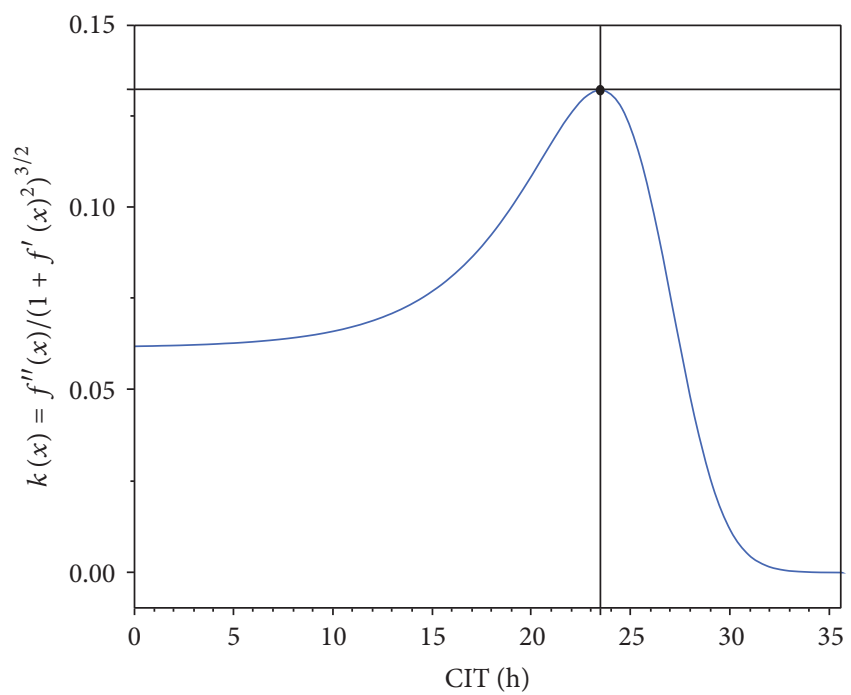

(b)

FIGURE 2: (a) Increments of odds ratios (OR) for delayed graft function were calculated and plotted per increment of CIT-hours. A mechanistic asymptotic regression function $f(x)=A \cdot\left(1+k \cdot e^{(I \cdot x)}\right)(A=$ asymptotic, $k=$ scale, and $I=$ increment $)$ with best estimated fit was chosen for further calculations. The function $f(x)=0.4175662 \cdot\left(1+0,035169 \cdot e^{(0.196467 \cdot x)}\right)$ (black line) was finally identified with lowest SSE $=10.3141$ and best $R^{2}=0.94$ (a). (b) The point of highest acceleration in risk increment was then calculated by insertion of the regression equation $f(x)=0.4175662 \cdot\left(1+0,035169 \cdot e^{(0.196467 \cdot x)}\right)$ into the curvature formula $k(x)=f^{\prime \prime}(x) /\left(1+f^{\prime}(x)^{2}\right)^{3 / 2}$ with $k_{\max }=0.13$ to 23.5 hours at an odds ratio of 1.9 (cross hairs at black (a) and blue lines (b)). The calculated CIT cut-off of $23.5 \mathrm{~h}$ was then used in univariable regression analysis to calculate the risk of delayed graft function development for CIT $>23.5 \mathrm{~h}$ to a hazard ratio of 3.713 (CI 2.215-6.225; $p<0.001$ ).

5,6 , and 7). There was no necessity for imputation of missing data.

3.2. Time Intervals for Day- and Nighttime Surgery. After several permutations (data not shown) the following 3-hour interval division of $24 \mathrm{~h}$ was identified as the time blocks that provide the best resolution with the highest significance levels and the highest calculable hazard ratios for the investigated study endpoints: 12 PM-3 AM, 3 AM-6 AM, 6 AM-9 AM, 9 AM-12 AM, 12 AM-3 PM, 3 PM-6 PM, 6 PM-9 PM, and 9 PM-12 PM (Table 1).

3.3. Surgical Experience and Teaching Operations during Daytime Shifts and Night Shifts. There were no significant differences between the frequencies of individual surgeons' postoperative complications that caused subsequent reoperations in each investigated three-hour interval $(p<0.05$, $\mathrm{Chi}^{2}$ ). The proportion of teaching operations during the critical hour from $3 \mathrm{AM}$ to $6 \mathrm{AM}$ was different neither to the extreme with lowest (9 PM-12 AM) nor to the extreme with highest (6 AM-9 AM) proportion of teaching operations ( $p>0.05, \mathrm{Chi}^{2}$ test) (Table 2, Supplemental Figure a). The variances of surgical experience as expressed in calculated CUSUM of the operating primary surgeons between all $3 \mathrm{~h}$ intervals were not significantly different ( $p=0.627$, Levene's test) (Table 2, Supplemental Figure b). The 1st surgeons CUSUM had no significant impact on any of the investigated adverse events (Tables 3, 4, 5, 6, and 7).
3.4. Circadian Daytime Related Risk Development. In the next step we analyzed how big the risk was for any of the binary endpoints within each of the $3 \mathrm{~h}$ daytime intervals. Univariable binary regression analysis showed a substantial increase in the risk for reoperation, perioperative graft loss, and perioperative graft loss due to surgical reasons for the $3 \mathrm{AM}$ to $6 \mathrm{AM}$ time interval. In contrast we observed a reduction in risk of delayed graft function for the $3 \mathrm{AM}$ to $6 \mathrm{AM}$ night shift interval, although this tendency was statistically not significant (Table 1).

3.5. Independent Risk Factors for Reoperation. Risk-adjusted multivariable regression analyses revealed that donor age, donor BMI, and night shift surgery from $3 \mathrm{AM}$ to $6 \mathrm{AM}$ were significant independent risk factors for reoperation during the initial hospital stay. Stenting of ureter anastomosis on the other hand significantly reduced the risk of reoperation (Table 3).

3.6. Independent Risk Factors for Perioperative Graft Loss. Donor age, night shift from $3 \mathrm{AM}$ to $6 \mathrm{AM}$, and recipient BMI were independent significant risk factors for perioperative graft loss (Table 4). More than one arterial anastomosis was a significant hazard in the univariate regression but did not reach significance $(p=0.069)$ in the multivariate regression analysis.

3.7. Independent Risk Factors for Perioperative Graft Loss due to Surgical Reasons. Night shift between 3 AM and 6 AM, recipient $\mathrm{BMI}$, and more than one arterial anastomosis 
TABLE 4: Regression analysis of the risks for perioperative graft loss $(n=55)$. Shown are the results of univariable and multivariable binary regression analyses to determine the odds ratios of the investigated variables for the risk of perioperative graft loss $(n=55)$ during primary hospitalization period. Analyzed were all 1262 cases with standard kidney transplantations into nonpreoperated sites between 1 January 2000 and 31 October 2013. Included into risk-adjusted multivariable analyses were only transplant variables with a $p$ value $<0.2$ in univariable regression analyses.

\begin{tabular}{|c|c|c|c|c|c|c|c|c|c|c|}
\hline \multirow[t]{2}{*}{ Continuous variables } & \multicolumn{4}{|c|}{ Descriptive statistics } & \multicolumn{3}{|c|}{$\begin{array}{l}\text { Univariable binary } \\
\text { regression }\end{array}$} & \multicolumn{3}{|c|}{$\begin{array}{c}\text { Risk-adjusted } \\
\text { multivariable binary } \\
\text { regression }\end{array}$} \\
\hline & Med & Mean & Range & $\begin{array}{l}\mathrm{MV}^{\S} \\
n / \%\end{array}$ & $p$ & OR & $95 \% \mathrm{CI}$ & $p$ & OR & $95 \% \mathrm{CI}$ \\
\hline Donor age [yr.] & 53 & 52 & $5-88$ & $4 / 0.3$ & 0.003 & 1.029 & $1.009-1.048$ & 0.017 & 1.027 & $1.005-1.050$ \\
\hline Donor BMI $\left[\mathrm{kg} / \mathrm{m}^{2}\right]$ & 25 & 25 & $15-38$ & $4 / 0.3$ & 0.086 & 1.051 & $0.993-1.112$ & 0.276 & \multicolumn{2}{|c|}{ Not calculated ${ }^{2}$} \\
\hline Donor creatinine $[\mu \mathrm{mol} / \mathrm{l}]$ & 70 & 91 & $0-8840$ & 0 & 0.835 & 1.000 & $0.998-1.002$ & \multirow{2}{*}{\multicolumn{3}{|c|}{ Not selected $^{1}$}} \\
\hline Recipient age [yr.] & 55 & 54 & $18-77$ & 0 & 0.580 & 1.006 & $0.985-1.028$ & & & \\
\hline Recipient BMI $\left[\mathrm{kg} / \mathrm{m}^{2}\right]$ & 25 & 25 & $15-38$ & $35 / 2.8$ & 0.032 & 1.080 & $1.007-1.158$ & 0.016 & 1.103 & $1.019-1.194$ \\
\hline CIT [min.] & 858 & 916 & $125-2458$ & $65 / 5.2$ & 0.059 & 1.001 & $1.000-1.001$ & \multicolumn{3}{|c|}{$0.481 \quad$ Not calculated $^{2}$} \\
\hline 1st surgeon's CUSUM & 29 & 46 & $1-361$ & $12 / 1.0$ & 0.615 & 1.001 & $0.997-1.006$ & \multicolumn{3}{|c|}{ Not selected $^{1}$} \\
\hline Categorical variables & & & $N$ & $\begin{array}{l}\mathrm{MV}^{\S} \\
n / \%\end{array}$ & $p$ & OR & $95 \% \mathrm{CI}$ & $p$ & OR & $95 \% \mathrm{CI}$ \\
\hline Night shift surgery $3 A M-6 A M$ & & & 25 & 0 & 0.004 & 5.131 & $1.711-15.389$ & 0.003 & 5.543 & $1.758-17.47$ \\
\hline Recipient's right fossa & & & 740 & 0 & 0.500 & 0.844 & $5.15-1.381$ & \multirow{2}{*}{\multicolumn{3}{|c|}{ Not selected ${ }^{1}$}} \\
\hline Right donor kidney & & & 611 & 0 & 0.715 & 0.913 & $0.559-1.489$ & & & \\
\hline \multicolumn{11}{|l|}{ Number of arteries } \\
\hline One & & & 947 & \multirow{2}{*}{0} & \multicolumn{3}{|c|}{ Reference } & \multirow{2}{*}{\multicolumn{3}{|c|}{$\begin{array}{l}\text { Collinearity with number } \\
\text { of arterial anastomoses }\end{array}$}} \\
\hline$>$ one & & & 315 & & 0.043 & 1.716 & $1.017-2.893$ & & & \\
\hline \multicolumn{11}{|l|}{ Number of arterial anastomoses } \\
\hline One & & & 1140 & \multirow{2}{*}{0} & \multicolumn{3}{|c|}{ Reference } & \multicolumn{3}{|c|}{ Reference } \\
\hline >one & & & 122 & & 0.060 & 1.853 & $0.974-3.525$ & 0.069 & Not & alculated $^{2}$ \\
\hline \multicolumn{11}{|l|}{ Number of veins } \\
\hline One & & & 1220 & \multirow{2}{*}{0} & \multicolumn{3}{|c|}{ Reference } & & & \\
\hline$>$ one & & & 42 & & 0.963 & 0.967 & $0.231-4.053$ & & & \\
\hline \multicolumn{11}{|l|}{ Numbers of venous anastomoses } \\
\hline One & & & 1261 & \multirow{2}{*}{0} & \multicolumn{3}{|c|}{ Reference } & \multirow{2}{*}{\multicolumn{3}{|c|}{ Not selected $^{1}$}} \\
\hline >one & & & 1 & & 0.999 & 0.000 & 0.000 & & & \\
\hline \multicolumn{11}{|l|}{ Stenting of ureter anastomosis } \\
\hline Nonstented & & & 380 & \multirow{2}{*}{$5 / 0.4$} & \multicolumn{3}{|c|}{ Reference } & & & \\
\hline Stented & & & 877 & & 0.309 & 1.348 & $0.759-2.395$ & & & \\
\hline
\end{tabular}

${ }^{1}$ Not selected because of a $p$ value $>0.2$ in univariable analyses.

${ }^{2}$ Odds ratios and $95 \%$ CI were not calculated because of a $p$ value $>0.05$ in multivariable analyses.

${ }^{\S}$ Little's MCAR test: Chi-Square $=31.909, \mathrm{DF}=33$, and $p=0.521$.

were identified as independent significant risk factors for perioperative graft loss due to surgical reasons (Table 5).

3.8. Independent Risk Factors Risk Factors for Delayed Graft Function. Donor age, recipient BMI, and cold ischemic time were significant independent risk factors for delayed graft function (Table 6).

3.9. Independent Risk Factors for Hospital Discharge on Dial$y$ sis. Donor age was the only independent significant risk factor for hospital discharge on hemodialysis (Table 7).
3.10. Modelling of the Nonlinear Regression Function of the CIT Dependent Risk for Delayed Graft Function and Calculation of the Cut-Off Point of Highest Risk Increment. Multivariable regression analyses revealed that CIT was relevant only for the endpoint of delayed graft function. The calculated odds ratios (OR) for delayed graft function per CIT-hour were plotted and a nonlinear regression function with best estimated fit was chosen. The resulting mechanistic asymptotic regression function $f(x)=0.4175662 \cdot(1+0,035169$. $\left.e^{(0.196467 \cdot x)}\right)$ (Figure 2(a)) with smallest SSE fit $\left(R^{2}=0.94\right)$ was then implemented into the two-dimensional curvature 
TABLE 5: Regression analysis of the risks of perioperativegraft loss due to surgical reasons $(n=21)$. Shown are the results of univariable and multivariable binary regression analyses to determine the odds ratios of the investigated variables for the risk of perioperativegraft loss due to surgical reasons $(n=21)$. Analyzed were all 1262 cases with standard kidney transplantations into nonpreoperated sites between 1 January 2000 and 31 October 2013. Included into risk-adjusted multivariable analyses were only transplant variables with a $p$ value $<0.2$ in univariable regression analyses.

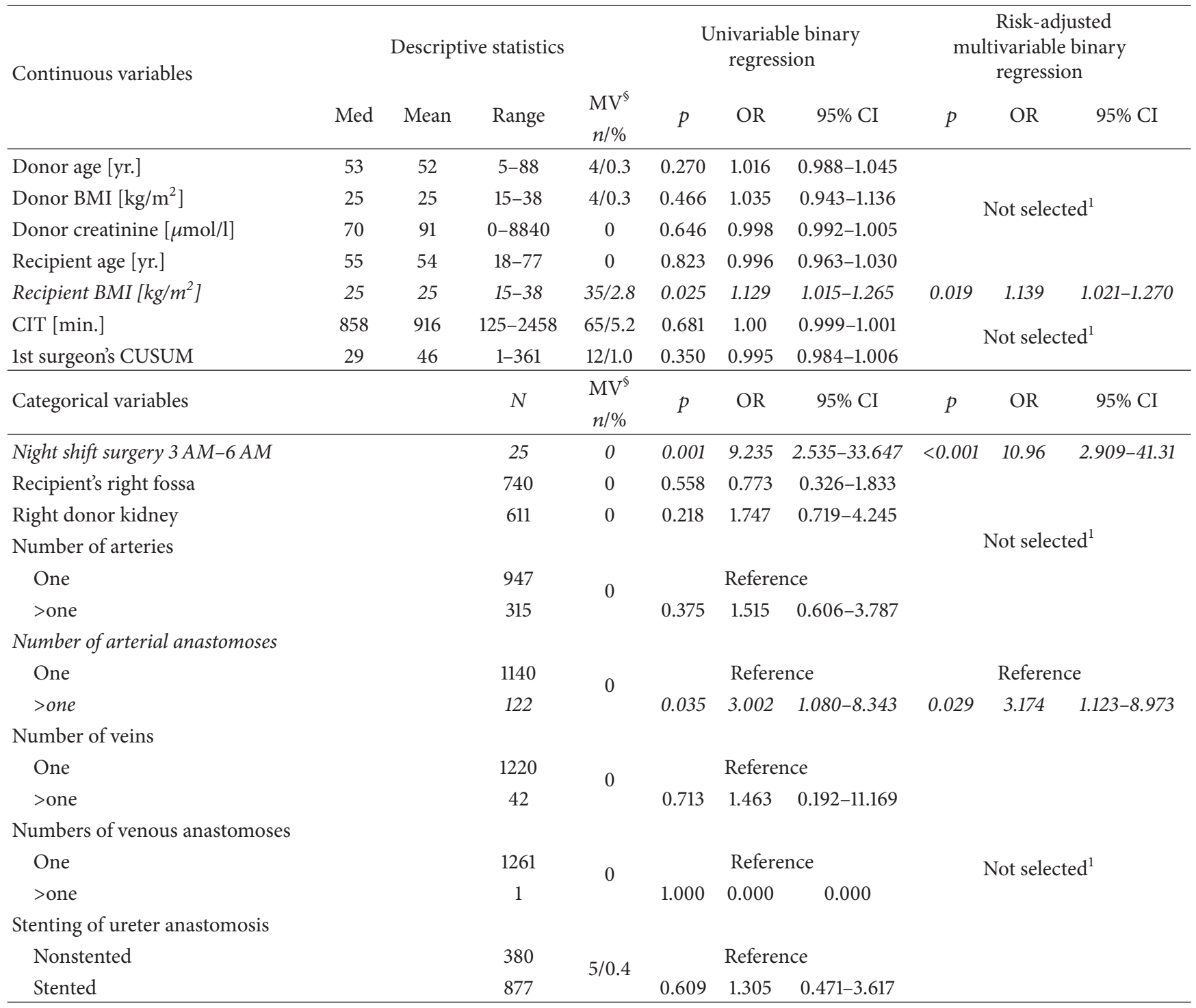

${ }^{1}$ Not selected because of a $p$ value $>0.2$ in univariable analyses.

${ }^{\S}$ Little's MCAR test: Chi-Square $=31.909, \mathrm{DF}=33$, and $p=0.521$.

formula [27] $k(x)=f^{\prime \prime}(x) /\left(1+f^{\prime}(x)^{2}\right)^{3 / 2}$ for the calculation of highest risk acceleration. The highest risk acceleration $\left(k_{\max }\right.$ : the point at which the risk increment changes the quickest) was then identified using the first derivate $k^{\prime}$ of that risk acceleration function at 23.5 hours (Figure $2(\mathrm{~b}), k_{\max }$. $=0.13$ ) and was defined as the CIT cut-off for delayed graft function. The parameter estimates for 23 hours and 24 hours were 0.578 (OR 1.783; CI-95\%: 1.07-2.97) and 0.661 (OR 1.937; CI-95\%: 1.06-3.542), respectively. All kidney transplantations were then categorized into belonging to the group either below or above the calculated CIT cut-off of $23.5 \mathrm{~h}$. The new variable above CIT cut-off [yes/no] was then included into a binary regression analysis and the hazard ratio for delayed graft function beyond $23.5 \mathrm{~h}$ was calculated to $\mathrm{OR}=3.713$ (CI 2.215-6.225).

\section{Discussion}

This study reports for the first time that transplantation in the early morning hours between $3 \mathrm{AM}$ and $6 \mathrm{AM}$ is an independent significant risk factor for early outcome after kidney transplantation (Tables 1 and 3-7). This study is also an in-depth analysis about the significance of cold ischemic time (CIT) for the outcome of kidney transplantation and about the methodology of how to calculate risks that are mediated by time related variables such as CIT. We show that 
TABLE 6: Regression analysis of the risks for delayed graft function $(n=272)$. Shown are the results of univariable and multivariable binary regression analyses to determine the odds ratios of the investigated variables for the risk of delayed graft function $(n=272)$. Dialysis data were retrospectively available for 985 cases. Patients with perioperative graft nephrectomy and with discharge on dialysis were censored $(n=102)$. Analyzed were all remaining cases $(n=883)$. Included into risk-adjusted multivariable analyses were only transplant variables with a $p$ value $\leq 0.2$ in univariable regression analyses.

\begin{tabular}{|c|c|c|c|c|c|c|c|c|c|c|}
\hline \multirow[t]{2}{*}{ Continuous variables } & \multicolumn{4}{|c|}{ Descriptive statistics } & \multicolumn{3}{|c|}{$\begin{array}{l}\text { Univariable binary } \\
\text { regression }\end{array}$} & \multicolumn{3}{|c|}{$\begin{array}{l}\text { Risk-adjusted } \\
\text { multivariable binary } \\
\text { regression }\end{array}$} \\
\hline & Med & Mean & Range & $\begin{array}{l}\mathrm{MV}^{\S} \\
n / \%\end{array}$ & $p$ & OR & $95 \% \mathrm{CI}$ & $p$ & OR & $95 \% \mathrm{CI}$ \\
\hline Donor age [yr.] & 54 & 53 & $6-88$ & $3 / 0.3$ & $<0.001$ & 1.018 & $1.008-1.027$ & 0.001 & 1.017 & $1.010-1.033$ \\
\hline Donor BMI $\left[\mathrm{kg} / \mathrm{m}^{2}\right]$ & 26 & 26 & $12-52$ & $3 / 0.3$ & 0.510 & 1.011 & $0.978-1.046$ & \multirow{2}{*}{\multicolumn{3}{|c|}{ Not selected $^{1}$}} \\
\hline Donor creatinine $[\mu \mathrm{mol} / \mathrm{l}]$ & 68 & 95 & $0-8408$ & 0 & 0.776 & 1.000 & $1.000-1.000$ & & & \\
\hline Recipient age [yr.] & 56 & 54 & $18-77$ & 0 & 0.013 & 1.015 & $1.003-1.027$ & 0.742 & \multicolumn{2}{|c|}{ Not calculated $^{2}$} \\
\hline Recipient BMI $\left[\mathrm{kg} / \mathrm{m}^{2}\right]$ & 25 & 25 & $15-38$ & $14 / 1.6$ & 0.001 & 1.068 & $1.029-1.109$ & 0.001 & 1.074 & $1.031-1.119$ \\
\hline CIT [min.] & 785 & 846 & $125-2286$ & $16 / 1.9$ & $<0.001$ & 1.002 & $1.001-1.002$ & $<0.001$ & 1.002 & $1.001-1.002$ \\
\hline 1st surgeon's CUSUM & 29 & 46 & 1-361 & $5 / 0.6$ & 0.770 & 1.000 & $0.997-1.002$ & \multicolumn{3}{|c|}{ Not selected ${ }^{1}$} \\
\hline Categorical variables & & & $N$ & $\begin{array}{l}\mathrm{MV}^{\S} \\
n / \%\end{array}$ & $p$ & OR & $95 \% \mathrm{CI}$ & $p$ & OR & $95 \% \mathrm{CI}$ \\
\hline Night shift surgery 3 AM-6 AM & & & 16 & 0 & 0.303 & 0.515 & $0.146-1.822$ & \multicolumn{3}{|c|}{ Not selected $^{1}$} \\
\hline Recipient's right fossa & & & 555 & 0 & 0.013 & 0.689 & $0.514-0.924$ & \multirow[t]{2}{*}{0.065} & \multirow{2}{*}{\multicolumn{2}{|c|}{ Not calculated $^{2}$}} \\
\hline Right donor kidney & & & 425 & 0 & 0.618 & 1.076 & $0.808-1.432$ & & & \\
\hline Number of arteries & & & & & & & & \multirow{3}{*}{\multicolumn{3}{|c|}{ Not selected ${ }^{1}$}} \\
\hline One & & & 667 & \multirow[t]{2}{*}{0} & \multicolumn{3}{|c|}{ Reference } & & & \\
\hline >one & & & 216 & & 0.432 & 1.146 & $0.822-1.599$ & & & \\
\hline \multicolumn{11}{|l|}{ Number of arterial anastomoses } \\
\hline One & & & 802 & \multirow{2}{*}{0} & \multicolumn{3}{|c|}{ Reference } & \multicolumn{3}{|c|}{ Reference } \\
\hline >one & & & 81 & & 0.006 & 1.927 & $1.212-3.064$ & 0.087 & Not & lculated ${ }^{2}$ \\
\hline \multicolumn{11}{|l|}{ Number of veins } \\
\hline One & & & 852 & \multirow{2}{*}{0} & \multicolumn{3}{|c|}{ Reference } & & & \\
\hline$>$ one & & & 31 & & 0.835 & 0.920 & $0.418-2.025$ & & & \\
\hline \multicolumn{11}{|l|}{ Number of venous anastomoses } \\
\hline One & & & 882 & \multirow{2}{*}{0} & & Refere & & \multirow{2}{*}{\multicolumn{3}{|c|}{ Not selected ${ }^{1}$}} \\
\hline >one & & & 1 & & 1.000 & 0.000 & 0.000 & & & \\
\hline \multicolumn{11}{|l|}{ Stenting of ureter anastomosis } \\
\hline Nonstented & & & 214 & \multirow{2}{*}{0} & \multicolumn{3}{|c|}{ Reference } & & & \\
\hline Stented & & & 669 & & 0.161 & 0.791 & $0.571-1.098$ & & & \\
\hline
\end{tabular}

${ }^{1}$ Not selected due to $p$ value $>0.2$ in univariable analyses.

${ }^{2}$ Odds ratios and $95 \%$ CI were not calculated because of a $p$ value $>0.05$ in multivariable analyses.

${ }^{\S}$ Little's MCAR test: Chi-Square $=23.458, \mathrm{DF}=23$, and $p=0.434$.

risk balancing between nighttime kidney transplantation and cold ischemic time is always necessary, even if this violates the holy grail of CIT reduction.

Variables that reflect the surgical complexity such as the number of renal arteries and veins [14, 28, 29], length of ureter and blood vessels [6], recipient BMI [30-32], and recipient age [33] as well as immunological parameters [16, 17] and patient comorbidities [13] cannot be changed by the operating surgeon on the day of surgery. As soon as a donor kidney is allocated these preconditions are unchangeable. CIT and the daytime of transplantation on the other hand can be influenced by the operating surgeon to some extent.
Therefore, it is interesting to note that the variables CIT and the onset time of a kidney transplantation between $3 \mathrm{AM}$ and $6 \mathrm{AM}$ are competing hazards for perioperative outcome.

Despite the small number of patients who underwent transplanting within the $3 \mathrm{AM}$ to $6 \mathrm{AM}$ interval it must be noted that initiation of transplantation during that interval significantly increased the risk of reoperation, perioperative graft loss, and graft loss due to surgical reasons (Tables 1 and $3-5$ ), while strikingly the relevance of prolonged CIT was negligible for all the studied endpoints, except the endpoint of delayed graft function (DGF), for which we identified a cut-off at 23.5 hours of CIT (Figure 2). This result is in line 
TABLE 7: Regression analysis of the risks for hospital discharge on dialysis $(n=102)$. Shown are the results of univariable and multivariable binary regression analyses to determine the odds ratios of the investigated variables for the risk of hospital discharge on dialysis $(n=102)$. Dialysis data were retrospectively available only for the period between 19 May 2003 and 31 Oct 2013. Analyzed were all cases $(n=985)$ with standard kidney transplantations into nonpreoperated sites. Included into risk-adjusted multivariable analyses were only transplant variables with a $p$ value $\leq 0.2$ in univariable regression analyses.

\begin{tabular}{|c|c|c|c|c|c|c|c|c|c|c|}
\hline \multirow[t]{2}{*}{ Continuous variables } & \multicolumn{4}{|c|}{ Descriptive statistics } & \multicolumn{3}{|c|}{$\begin{array}{l}\text { Univariable binary } \\
\text { regression }\end{array}$} & \multicolumn{3}{|c|}{$\begin{array}{l}\text { Risk-adjusted } \\
\text { multivariable binary } \\
\text { regression }\end{array}$} \\
\hline & Med & Mean & Range & $\begin{array}{l}\mathrm{MV}^{\S} \\
n / \%\end{array}$ & $p$ & OR & $95 \% \mathrm{CI}$ & $p$ & OR & $95 \% \mathrm{CI}$ \\
\hline Donor age [yr.] & 53 & 52 & $5-88$ & $3 / 0.3$ & $<0.001$ & 1.028 & $1.013-1.044$ & 0.001 & 1.030 & $1.012-1.048$ \\
\hline Donor BMI $\left[\mathrm{kg} / \mathrm{m}^{2}\right]$ & 25 & 26 & $12-52$ & $3 / 0.3$ & 0.275 & 1.026 & $0.980-0.1075$ & \multirow{2}{*}{\multicolumn{3}{|c|}{ Not selected ${ }^{1}$}} \\
\hline Donor creatinine $[\mu \mathrm{mol} / \mathrm{l}]$ & 70 & 91 & $0-8408$ & 0 & 0.552 & 0.999 & $0.996-1.002$ & & & \\
\hline Recipient age [yr.] & 56 & 54 & $18-77$ & 0 & 0.181 & 1.012 & $0.995-1.029$ & 0.418 & \multicolumn{2}{|c|}{ Not calculated $^{2}$} \\
\hline Recipient BMI $\left[\mathrm{kg} / \mathrm{m}^{2}\right]$ & 25 & 25 & $15-38$ & $33 / 3.4$ & 0.129 & 1.041 & $0.988-1.097$ & 0.178 & \multicolumn{2}{|c|}{ Not calculated $^{2}$} \\
\hline CIT [min.] & 858 & 917 & $125-2458$ & $6 / 0.6$ & 0.289 & 1.000 & $1.000-1.001$ & \multirow{2}{*}{\multicolumn{3}{|c|}{ Not selected ${ }^{1}$}} \\
\hline 1st surgeon's CUSUM & 29 & 46 & $1-361$ & $17 / 1.8$ & 0.975 & 1.000 & $0.996-1.004$ & & & \\
\hline Categorical variables & & & $N$ & $\begin{array}{l}\mathrm{MV}^{\S} \\
n / \%\end{array}$ & $p$ & OR & $95 \%$ CI & $p$ & OR & $95 \% \mathrm{CI}$ \\
\hline Night shift surgery 3 AM-6 AM & & & 20 & 0 & 0.163 & 2.212 & $0.725-6.747$ & 0.214 & Not & lculated $^{2}$ \\
\hline Right recipient's fossa & & & 614 & 0 & 0.229 & 0.775 & $0.512-1.174$ & \multirow{2}{*}{\multicolumn{3}{|c|}{ Not selected ${ }^{1}$}} \\
\hline Right donor kidney & & & 474 & 0 & 0.986 & 0.996 & $0.661-1.502$ & & & \\
\hline \multicolumn{11}{|l|}{ Number of arteries } \\
\hline One & & & 735 & \multirow{2}{*}{0} & \multicolumn{3}{|c|}{ Reference } & \multirow{2}{*}{\multicolumn{3}{|c|}{$\begin{array}{l}\text { Collinearity with number } \\
\text { of arterial anastomoses }\end{array}$}} \\
\hline >one & & & 250 & & 0.053 & 1.544 & $0.995-2.396$ & & & \\
\hline \multicolumn{11}{|l|}{ Number of arterial anastomoses } \\
\hline One & & & 888 & \multirow{2}{*}{0} & \multicolumn{3}{|c|}{ Reference } & \multicolumn{3}{|c|}{ Reference } \\
\hline >one & & & 97 & & 0.039 & 1.842 & $1.031-3.292$ & 0.066 & Not & lculated ${ }^{2}$ \\
\hline \multicolumn{11}{|l|}{ Number of veins } \\
\hline One & & & 950 & \multirow{2}{*}{0} & \multicolumn{3}{|c|}{ Reference } & & & \\
\hline >one & & & 35 & & 0.832 & 1.122 & $0.388-3.245$ & & & \\
\hline \multicolumn{11}{|l|}{ Number of venous anastomosis } \\
\hline One & & & 984 & \multirow{2}{*}{0} & & Refere & ace & \multirow{2}{*}{\multicolumn{3}{|c|}{ Not selected $^{1}$}} \\
\hline$>$ one & & & 1 & & 1.000 & 0.000 & 0.000 & & & \\
\hline \multicolumn{11}{|l|}{ Stenting of ureter anastomosis } \\
\hline Nonstented & & & 242 & \multirow{2}{*}{$3 / 0.3$} & \multicolumn{3}{|c|}{ Reference } & & & \\
\hline Stented & & & 740 & & 0.376 & 0.811 & $0.510-1.290$ & & & \\
\hline
\end{tabular}

${ }^{1}$ Not selected because of a $p$ value $>0.2$ in univariable analyses.

${ }^{2}$ Odds ratios and $95 \%$ CI were not calculated because of a $p$ value $>0.05$ in multivariable analyses.

${ }^{\S}$ Little’s MCAR test: Chi-Quadrat $=26.171, \mathrm{DF}=33$, and $p=0.795$.

with the previously published findings of the Collaborative Transplant Study (CTS), which reported on more than 60,000 cases that graft survival was only marginally influenced by ischemia times up to 24 hours [24].

When putting these two findings together the logical consequence is to avoid transplantations between $3 \mathrm{AM}$ and $6 \mathrm{AM}$ in the morning, at least as long as CIT is not prolonged above the turning point of 23.5 hours. Following this approach would replace the so far undisputed transplant dogma of CIT reduction by any means with a strategy of finding a meaningful balance between two possibly competing hazards, CIT and daytime of surgery.
Not only is it a judgment of common sense that working at late night hours inevitably induces increased error and defect rates, but also it has been shown extensively that sleep deprivation and mental fatigue negatively impact on key cognitive functions such as attention [34-37], working memory $[38,39]$, risk assessment [40], and decision making [41]. Thus it is no surprise that there are a number of studies that found that surgery during night shifts is hazardous and potentially deteriorates quality and outcome in comparison to daytime surgery [42-44]. However, numerous studies reported that day and night shift surgery are not different with respect to outcome [45-47]. The explanation of these contradictory 
results is reasonably simple, at least at face value. All of these latter studies defined night shift surgery under inclusion of evening hours (e.g., 8 PM-8 AM [48], 4 PM-6 AM [44], and 3 PM-3 AM [43]) and failed to scope at those hours of the night between $12 \mathrm{PM}$ and $6 \mathrm{AM}$ when the circadian rhythm most persuasively demands sleeping [49]. In this context it must be noted that conversion of continuous variables such as daytime [hh:mm:ss] into a binary format (e.g., 8 PM-6 AM versus 7 AM-7 PM) introduces a significant loss of resolution. As a consequence, possible risk increments are easily overseen. In order to meet that concern and to enhance the contrast of the investigated daytime variable it is important to set the boundaries for binary conversion not arbitrarily but with respect to plausible causation. For this study we have investigated several permutations of different day- and nighttime blocks. These investigations showed that the finally chosen 3-hour intervals were identified as time blocks that provide the best resolution with the highest significance levels and the highest calculable hazard ratios for the investigated study endpoints (Table 1). This approach resulted in the finding that the time interval between $3 \mathrm{AM}$ and $6 \mathrm{AM}$ was associated with significantly increased complications after kidney transplantation, which is a plausible result with respect to a surgeons' fatigue caused by sleep deprivation and the fact that humans are not nocturnal mammals and do not express the typical phenotypes of nocturnal animals. Therefore, the night shift hours from $12 \mathrm{PM}$ to $6 \mathrm{AM}$ can be intuitively understood as a hazard in comparison to daylight surgery. Analyzing deteriorated outcomes and a possible causation by night shift surgery though requires setting the boundaries of night shift hours in a way so that the time interval likely correlates with sleep deprivation and laps of circadian rhythm.

The surgeon usually has to organize and schedule the transplantation procedure. This involves informing involved personnel (intensive care unit, anesthesiologist, scrub nurses, and surgical team), carrying out the recipient examination and repetitive communication with the transplant coordinator. Further, the donor organ needs to be inspected and prepared ahead of the actual start of anesthesia. Consequently, the transplant surgeon usually is up on his feet at least one hour before the actual start of the operating procedure. The critical time period of $3 \mathrm{AM}$ to $6 \mathrm{AM}$, which reflects the start-time of the operation, usually requires a wake-up call at least 1-2 hours earlier. Moreover, if the transplant center has no specialized transplant team in stand-by, who could be called in to perform an organ transplantation at any time, then the in-house on-call surgeons, who are often involved in other emergency procedures and consultations, will have to perform the transplantation in between all other emergency procedures, as is the case in our center. This implies that the on-call surgeons frequently have no time to rest before the onset of the transplant procedure, which possibly explains the high risk increment during the last hours of a 24-hour night shift. There were no differences in neither age, seniority, experience, nor training, when comparing daytime shifts and night shifts. Respectively, there were no differences in seniority and transplant surgery experience: for neither the surgeons, nor anesthesiologists, nor nursing staff or any other caregivers. This may be different from institution to institution and may thus lead to different results.

Theoretically there is a possible impact of surgical support staff's fatigue on surgical outcome as well, because the surgical support staff has similar day- and nighttime shifts. But the staff is not responsible for and not involved in the management process of emergencies, such as interdisciplinary telephone conferences, ER visits, patient examinations, discussion of CT scan results, and other time consuming nightly events, which do keep the surgeons from sleeping. Because the staff is not involved in processing of nonsurgical emergencies and because the staff of the general/ transplant surgery department is exclusively assigned to the general/transplant surgery team, their workload during night shifts is significantly less.

Another possible influence might be the experience level of the supporting surgical staff. But the staff's team always consisted of one senior scrub nurse and one learning scrub nurse, who were randomly assigned to the surgeons' night shift team. There was no systematic hazardous team-bias that possibly could have altered the quality of surgery during night shifts or certain night shift hours.

Fechner et al. [48], even though they did not investigate surgery related complications of the primary hospitalization period when most surgery related complications usually unfold, found that night shift surgery prevailed as a significant hazard in their analysis and concluded that night shift surgery with the goal of reducing CIT at any costs might not be a wise decision.

In our current analysis delayed graft function significantly correlated with CIT prolongation (Table 6), while in contrast the period from $3 \mathrm{AM}$ to $6 \mathrm{AM}$ was advantageous. This observation is plausible, apparently due to the fact that CIT of kidneys transplanted between $3 \mathrm{AM}$ and $6 \mathrm{AM}$ was significantly shorter as compared to kidneys that had been transplanted outside the 3AM-6 AM time interval (data not shown). Furthermore, CIT did not stratify as a major risk for discharge on dialysis (Table 7) and was neither a significant independent risk factor for reoperation (Table 3), perioperative graft loss (Table 4), nor a risk for graft loss due to identified surgical reasons (Table 5).

We found that more than one arterial anastomosis was a significant risk for perioperative graft loss due to surgical reasons (Table 5), while the number of arterial anastomoses did not stratify as a hazard for perioperative graft loss in general (Table 4). We also confirm the findings of others [30, 31] that recipient obesity is a risk for delayed graft function and surgical complications. However, obesity was no independent significant risk factor for discharge on dialysis (Table 7).

One consequence of intentional shifting of the start-time of a transplant operation from the $3 \mathrm{AM}-6 \mathrm{AM}$ interval to a day shift interval after $6 \mathrm{AM}$ is the likely collisions with scheduled subsequent elective surgeries. Our data though justifies the postponing of the elective surgery schedule in order to avoid likely higher complication rates of night shift kidney transplantations as in our opinion these aspects outweigh the negative consequences of a delayed elective surgeries schedule, because higher rates of complications not 
TABLE 8: Literature about CIT-impact on kidney transplantation outcome.

\begin{tabular}{|c|c|c|c|c|c|c|}
\hline Authors & Year & Endpoint & $\begin{array}{l}\text { Number of CIT } \\
\text { intervals }\end{array}$ & CIT interval details & $\begin{array}{l}\text { Resolution } \\
\text { [hours] }\end{array}$ & $\begin{array}{c}\text { OR calculation method } \\
\text { [stepwise forward/blockwise } \\
\text { two-sided] }\end{array}$ \\
\hline Debout et al. [18] & 2015 & $\begin{array}{c}\text { Graft failure, } \\
\text { death }\end{array}$ & 4 & $\begin{array}{l}6-16 \mathrm{~h}, 16-24 \mathrm{~h}, \\
24-36 \mathrm{~h},>36 \mathrm{~h}\end{array}$ & 8 and 12 & Blockwise two-sided \\
\hline Gill et al. [19] & 2014 & DGF & 7 & $\begin{array}{c}0-6 \mathrm{~h}, 6-12 \mathrm{~h}, 12-18 \mathrm{~h}, \\
18-24 \mathrm{~h}, 24-30 \mathrm{~h}, \\
30-36 \mathrm{~h},>36 \mathrm{~h}\end{array}$ & 6 & Blockwise two-sided \\
\hline Sert et al. [20] & 2014 & DGF & 3 & $\begin{array}{l}0-10 \mathrm{~h}, 10-20 \mathrm{~h}, \\
20-30 \mathrm{~h},>30 \mathrm{~h}\end{array}$ & 10 & Blockwise two-sided \\
\hline van der Vliet et al. [21] & 2011 & $\begin{array}{l}\text { DGF, } 5 \text { yr graft } \\
\text { survival }\end{array}$ & 5 & $\begin{array}{c}0-16 \mathrm{~h}, 16-20 \mathrm{~h} \\
21-25 \mathrm{~h}, 26-30 \mathrm{~h} \\
>30 \mathrm{~h}\end{array}$ & 4 and 16 & Blockwise two-sided \\
\hline Quiroga et al. [22] & 2006 & DGF, AR & 5 & $\begin{array}{c}\text { 5-17 h, 18-20 h, } \\
21-24 \mathrm{~h}, 25-31 \mathrm{~h}, \\
>32 \mathrm{~h}\end{array}$ & $3,4,5,7,13$ & Blockwise two-sided \\
\hline Su et al. [23] & 2004 & Graft failure & 6 & $\begin{array}{c}0-8 \mathrm{~h}, 9-16 \mathrm{~h}, 17-24 \mathrm{~h}, \\
25-36 \mathrm{~h}, 37-48 \mathrm{~h}, \\
>48 \mathrm{~h} \\
\end{array}$ & 8 and 12 & Blockwise two-sided \\
\hline Opelz [24] & 2004 & Graft failure & 5 & $\begin{array}{c}0-6 \mathrm{~h}, 7-12 \mathrm{~h}, 13-24 \mathrm{~h} \\
25-36 \mathrm{~h},>36 \mathrm{~h}\end{array}$ & 6 and 12 & Blockwise two-sided \\
\hline Smits et al. [25] & 2000 & Graft failure & 4 & $\begin{array}{c}0-18 \mathrm{~h}, 19-24 \mathrm{~h} \\
25-36 \mathrm{~h},>37 \mathrm{~h}\end{array}$ & 5 and 18 & Blockwise two-sided \\
\hline Ojo et al. [26] & 1997 & DGF & 4 & $\begin{array}{c}0-12 \mathrm{~h}, 13-24 \mathrm{~h} \\
25-36 \mathrm{~h} \\
>36 \mathrm{~h}\end{array}$ & 12 & Blockwise two-sided \\
\hline
\end{tabular}

only affect each transplanted patient, but also have substantial negative economic consequences for the hospital as well.

Pulsatile perfusion preservation could be a means to avoid delayed graft function caused by prolonged CIT [50] and may be a valuable tool if CIT prolongation past the identified cut-off of 23.5 hours might be unavoidable.

The conventional approach to odds ratio calculations for CIT-associated risks usually is a comparison of a predefined CIT interval against the mean risk that lies outside this predefined interval (two-sided; before and after) [18-20, 2226, 51] (Table 8). This conventional approach ignores the fact that CIT is a continuous and linear progressive variable and that any risk which is dependent from cold ischemia is a function of time also. But for the calculation of a risk development as a function of any continuous variable it is necessary to calculate the risk increments for each step of CIT category progression. And this is only possible if CIT is converted into a categorical variable in a cumulative stepwise forward fashion. But to our knowledge there are no published studies that have utilized such a stepwise statistical analysis of CIT-minutes or CIT-hours against any study endpoint. All published statistical analysis used a blockwise two-sided risk calculation [18-20, 22-26, 51, 52] (Table 8).

Furthermore, when converting a continuous variable to a categorical variable it is necessary to generate categorical steps that are small enough. Otherwise, significant risk increments or any nonlinear risk development is artificially concealed due to lack of resolution. Most published analyses though are based upon CIT categorizations with resolutions ranging from 6 to 12 hours $[18,19,23-26]$. In some studies CIT was even divided only in a binary fashion [53, 54]. Even though some authors have claimed to have shown that each additional hour of CIT significantly increases the risk for graft failure [18], none of them actually made use of 1-hour CIT intervals to calculate the risk increments.

\section{Conclusion}

This study demonstrates a new mathematical method for calculating the cut-off value for the largest CIT-mediated risk increment for adverse early outcomes such as delayed graft function. The proposed method for calculating time related risk increments and cut-offs utilizes a cumulative stepwise forward categorization of CIT. We believe that this approach is appropriate when the mathematical relation between a continuous variable such as time and the odds ratio for an adverse event is unknown. In detail, this method allowed the deduction of a nonlinear regression function with the highest SSE and $R^{2}$ value to describe the relation of CIT on the $x$-axis with the stepwise calculated odds ratios for DGF on the $y$-axis (Figure 2(a)).

Furthermore, we demonstrate that utilizing the curvature formula [27] $k(x)=f^{\prime \prime}(x) /\left(1+f^{\prime}(x)^{2}\right)^{3 / 2}$ in combination with nonlinear modelled regression equation is an elegant method to determine cut-offs and turning points of time related risks. We believe that this methodology is a novel approach and is of general relevance. The clinically relevant 
conclusions of this study are to avoid kidney transplantation between $3 \mathrm{AM}$ and $6 \mathrm{AM}$ in the morning in order to improve overall outcome, as long as prolongation of CIT is confined within 23.5 hours and that CIT is only relevant for the endpoint of delayed graft function but had no impact on discharge on dialysis, reoperation, or graft loss.

$\begin{array}{ll}\text { Abbreviations } \\ \text { AR: } & \text { Acute rejection } \\ \text { CI: } & \text { Confidence interval } \\ \text { CIT: } & \text { Cold ischemic time } \\ \text { CUSUM: } & \text { Cumulative summation } \\ \text { DGF: } & \text { Delayed graft function } \\ \text { INF: } & \text { Initial nonfunction } \\ \text { OR: } & \text { Odds ratio } \\ R^{2}: & \text { Residual sum of squares } \\ \text { RO: } & \text { Reoperation. }\end{array}$

\section{Competing Interests}

All authors declare that there is no conflict of interests that could be perceived as prejudicing the impartiality of the research reported.

\section{Authors' Contributions}

Nikos Emmanouilidis and Julius Boeckler participated in research design. Nikos Emmanouilidis, Julius Boeckler, Bastian P. Ringe, Alexander Kaltenborn, and Harald Schrem participated in the writing of the paper. Nikos Emmanouilidis, Julius Boeckler, Bastian P. Ringe, Frank Lehner, Jürgen Klempnauer, and Harald Schrem participated in the performance of the research. Nikos Emmanouilidis, Julius Boeckler, and Bastian P. Ringe participated in data acquisition. Nikos Emmanouilidis, Julius Boeckler, Alexander Kaltenborn, Hans Friedrich Koch, and Harald Schrem participated in data analysis. Nikos Emmanouilidis and Julius Boeckler contributed equally.

\section{Acknowledgments}

The work of the authors Alexander Kaltenborn and Harald Schrem was supported by a grant from the German Federal Ministry of Education and Research (Reference no. 01EO1302).

\section{References}

[1] W. Gregoir, "Lateral uretero-vesical anastomosis with plastic formation of ureteral segment to replace excised portion," Acta Urologica Belgica, vol. 23, no. 1, pp. 32-37, 1955.

[2] A. Napolitano, D. Fortunelli, and A. Cancrini, "Clinical considerations on pyelo-ureteral and uretero-vesical plastic operations," Annali Italiani di Chirurgia, vol. 37, pp. 659-678, 1960.

[3] J. R. Salaman, A. G. Clarke, and D. L. Crosby, "The management of kidney transplants damaged during their removal from the donor," British Journal of Urology, vol. 46, no. 2, pp. 173-177, 1974.
[4] M. Charlesworth, G. Marangoni, and N. Ahmad, "High ureteric injury following multiorgan recovery: successful kidney transplant with Boari flap ureterocystostomy reconstruction," Arab Journal of Nephrology and Transplantation, vol. 4, no. 3, pp. 155$158,2011$.

[5] E. Benedetti, C. Troppmann, K. Giltingham et al., "Short- and long-term outcomes of kidney transplants with multiple renal arteries," Annals of Surgery, vol. 221, no. 4, pp. 406-414, 1995.

[6] M. Santangelo, G. Spinosa, S. Grassia et al., "In situ elongation patch in right kidney transplantation," Transplantation Proceedings, vol. 40, no. 6, pp. 1871-1872, 2008.

[7] G. Valeriani, V. Cerbone, E. Russo, D. Sciano, and P. De Rosa, "Bench surgery in right kidney transplantation," Transplantation Proceedings, vol. 42, no. 4, pp. 1120-1122, 2010.

[8] J. M. Barry and E. F. Fuchs, "Right renal vein extension in cadaver kidney transplantation," Archives of Surgery, vol. 113, no. 3, article no. 300, 1978.

[9] J. Szmidt, S. Frunze, M. Karolak, K. Makej, T. Sablinski, and S. Nazarewski, "Right renal vein extension technique in human kidney transplantation," European Urology, vol. 16, no. 3, pp. 204-206, 1989.

[10] A. Arnau, E. Rodrigo, E. Miñambres et al., "Prediction of kidney transplant outcome by donor quality scoring systems: expanded criteria donor and deceased donor score," Transplantation Proceedings, vol. 44, no. 9, pp. 2555-2557, 2012.

[11] F. K. Port, J. L. Bragg-Gresham, R. A. Metzger et al., "Donor characteristics associated with reduced graft survival: an approach to expanding the pool of kidney donors," Transplantation, vol. 74, no. 9, pp. 1281-1286, 2002.

[12] P. S. Rao, D. E. Schaubel, M. K. Guidinger et al., "A comprehensive risk quantification score for deceased donor kidneys: the kidney donor risk index," Transplantation, vol. 88, no. 2, pp. 231-236, 2009.

[13] P. Moreira, H. Sá, A. Figueiredo, and A. Mota, "Delayed renal graft function: risk factors and impact on the outcome of transplantation," Transplantation Proceedings, vol. 43, no. 1, pp. 100-105, 2011.

[14] K. Chabchoub, M. N. Mhiri, A. Bahloul et al., "Does kidney transplantation with multiple arteries affect graft survival?" Transplantation Proceedings, vol. 43, no. 9, pp. 3423-3425, 2011.

[15] B. Tisserand, B. Doré, G. Touchard, F. Bridoux, and J. Irani, "Long-term outcome of renal transplantation: impact of surgical complications on graft survival," Progres en Urologie, vol. 23, no. 2, pp. 113-120, 2013.

[16] C. Lefaucheur, A. Loupy, G. S. Hill et al., "Preexisting donorspecific HLA antibodies predict outcome in kidney transplantation," Journal of the American Society of Nephrology, vol. 21, no. 8, pp. 1398-1407, 2010.

[17] B. G. Solheim, A. Flatmark, E. Enger, J. Jervell, and E. Thorsby, "Influence of HLA-A, - B, -C, and -D matching on the outcome of clinical kidney transplantation," Transplantation Proceedings, vol. 9, no. 1, pp. 475-478, 1977.

[18] A. Debout, Y. Foucher, K. Trébern-Launay et al., "Each additional hour of cold ischemia time significantly increases the risk of graft failure and mortality following renal transplantation," Kidney International, vol. 87, no. 2, pp. 343-349, 2015.

[19] J. Gill, J. Dong, M. Eng, D. Landsberg, and J. S. Gill, "Pulsatile perfusion reduces the risk of delayed graft function in deceased donor kidney transplants, irrespective of donor type and cold ischemic time," Transplantation, vol. 97, no. 6, pp. 668-674, 2014. 
[20] I. Sert, H. Colak, C. Tugmen, S. M. Dogan, and C. Karaca, “The effect of cold ischemia time on delayed graft function and acute rejection in kidney transplantation," Saudi Journal of Kidney Diseases and Transplantation, vol. 25, no. 5, pp. 960-966, 2014.

[21] J. A. van der Vliet, M. C. Warlé, C. L. S. Cheung, S. Teerenstra, and A. J. Hoitsma, "Influence of prolonged cold ischemia in renal transplantation," Clinical Transplantation, vol. 25, no. 6, pp. E612-E616, 2011.

[22] I. Quiroga, P. McShane, D. D. H. Koo et al., "Major effects of delayed graft function and cold ischaemia time on renal allograft survival," Nephrology Dialysis Transplantation, vol. 21, no. 6, pp. 1689-1696, 2006.

[23] X. Su, S. A. Zenios, H. Chakkera, E. L. Milford, and G. M. Chertow, "Diminishing significance of HLA matching in kidney transplantation," American Journal of Transplantation, vol. 4, no. 9, pp. 1501-1508, 2004.

[24] G. Opelz, Unrelated living donors, short ischemia, HLA matching CTS Collaborative Transplant Study 2004: Newsletter 2, http://www.ctstransplant.org/public/newsletters/2004/gif/20042.html.

[25] J. M. A. Smits, H. C. Van Houwelingen, J. De Meester et al., "Permanent detrimental effect of nonimmunological factors on long-term renal graft survival: a parsimonious model of timedependency," Transplantation, vol. 70, no. 2, pp. 317-323, 2000.

[26] A. O. Ojo, R. A. Wolfe, P. J. Held, F. K. Port, and R. L. Schmouder, "Delayed graft function: risk factors and implications for renal allograft survival," Transplantation, vol. 63, no. 7, pp. 968-974, 1997.

[27] W. E. Curvatureeditor, Ed., MathWorld-A Wolfram Web Resource, 2016, http://mathworld.wolfram.com/Curvature.html.

[28] C. M. Alarcón, G. S. Pastor, P. Á. González et al., "Must we still be worried about multiple arteries in kidney transplantation?" Nephro-Urology Monthly, vol. 5, no. 1, pp. 692-696, 2012.

[29] E. Lechevallier, D. Bretheau, Y. Berland, M. Olmer, M. Rampal, and C. Coulange, "Outcome of kidney transplants with multiple arteries," Progres en Urologie, vol. 5, no. 3, pp. 370-376, 1995.

[30] J. L. Gore, P. T. Pham, G. M. Danovitch et al., "Obesity and outcome following renal transplantation," American Journal of Transplantation, vol. 6, no. 2, pp. 357-363, 2006.

[31] R. J. Lynch, D. N. Ranney, C. Shijie, D. S. Lee, N. Samala, and M. J. Englesbe, "Obesity, surgical site infection, and outcome following renal transplantation," Annals of Surgery, vol. 250, no. 6, pp. 1014-1020, 2009.

[32] D. Singh, J. Lawen, and W. Alkhudair, "Does pretransplant obesity affect the outcome in kidney transplant recipients?" Transplantation Proceedings, vol. 37, no. 2, pp. 717-720, 2005.

[33] P. J. Morris, R. J. Johnson, S. V. Fuggle, M. A. Belger, and J. D. Briggs, "Analysis of factors that affect outcome of primary cadaveric renal transplantation in the UK," The Lancet, vol. 354, no. 9185, pp. 1147-1152, 1999.

[34] H. P. Van Dongen, G. Maislin, J. M. Mullington, and D. F. Dinges, "The cumulative cost of additional wakefulness: dose-response effects on neurobehavioral functions and sleep physiology from chronic sleep restriction and total sleep deprivation," Sleep, vol. 26, no. 2, pp. 117-126, 2003.

[35] M. W. L. Chee, J. C. Tan, H. Zheng et al., "Lapsing during sleep deprivation is associated with distributed changes in brain activation," The Journal of Neuroscience, vol. 28, no. 21, pp. 5519$5528,2008$.

[36] J. Lim, W.-C. Wu, J. Wang, J. A. Detre, D. F. Dinges, and H. Rao, "Imaging brain fatigue from sustained mental workload: an ASL perfusion study of the time-on-task effect," NeuroImage, vol. 49, no. 4, pp. 3426-3435, 2010.
[37] M. A. S. Boksem, T. F. Meijman, and M. M. Lorist, "Effects of mental fatigue on attention: an ERP study," Cognitive Brain Research, vol. 25, no. 1, pp. 107-116, 2005.

[38] Q. Mu, A. Mishory, K. A. Johnson et al., "Decreased brain activation during a working memory task at rested baseline is associated with vulnerability to sleep deprivation," Sleep, vol. 28, no. 4, pp. 433-446, 2005.

[39] A. Gohar, A. Adams, E. Gertner et al., "Working memory capacity is decreased in sleep-deprived internal medicine residents," Journal of Clinical Sleep Medicine, vol. 5, no. 3, pp. 191-197, 2009.

[40] V. Venkatraman, S. A. Huettel, L. Y. M. Chuah, J. W. Payne, and M. W. L. Chee, "Sleep deprivation biases the neural mechanisms underlying economic preferences," Journal of Neuroscience, vol. 31, no. 10, pp. 3712-3718, 2011.

[41] V. Venkatraman, Y. M. L. Chuah, S. A. Huettel, and M. W. L. Chee, "Sleep deprivation elevates expectation of gains and attenuates response to losses following risky decisions," Sleep, vol. 30, no. 5, pp. 603-609, 2007.

[42] R. R. Kelz, T. T. Tran, P. Hosokawa et al., "Time-of-day effects on surgical outcomes in the private sector: a retrospective cohort study," Journal of the American College of Surgeons, vol. 209, no. 4, pp. 434.e2-445.e2, 2009.

[43] B. E. Lonze, A. Parsikia, E. L. Feyssa et al., "Operative start times and complications after liver transplantation," American Journal of Transplantation, vol. 10, no. 8, pp. 1842-1849, 2010.

[44] W. M. Ricci, B. Gallagher, A. Brandt, J. Schwappach, M. Tucker, and R. Leighton, "Is after-hours orthopaedic surgery associated with adverse outcomes?: a prospective comparative study," Journal of Bone and Joint Surgery, vol. 91, no. 9, pp. 2067-2072, 2009.

[45] T. J. George, G. J. Arnaoutakis, C. A. Merlo et al., "Association of operative time of day with outcomes after thoracic organ transplant," JAMA, vol. 305, no. 21, pp. 2193-2199, 2011.

[46] E. S. Orman, P. H. Hayashi, E. S. Dellon, D. A. Gerber, and A. S. Barritt IV, "Impact of nighttime and weekend liver transplants on graft and patient outcomes," Liver Transplantation, vol. 18, no. 5, pp. 558-565, 2012.

[47] A. Yaghoubian, A. H. Kaji, B. Putnam, and C. De Virgilio, "Trauma surgery performed by "sleep deprived" residents: are outcomes affected?" Journal of Surgical Education, vol. 67, no. 6, pp. 449-451, 2010.

[48] G. Fechner, C. Pezold, S. Hauser, T. Gerhardt, and S. C. Müller, "Kidney's nightshift, kidney's nightmare? Comparison of daylight and nighttime kidney transplantation: impact on complications and graft survival," Transplantation Proceedings, vol. 40, no. 5, pp. 1341-1344, 2008.

[49] C. B. Saper, T. E. Scammell, and J. Lu, "Hypothalamic regulation of sleep and circadian rhythms," Nature, vol. 437, no. 7063, pp. 1257-1263, 2005.

[50] R. J. Stratta, P. S. Moore, A. C. Farney et al., "Influence of pulsatile perfusion preservation on outcomes in kidney transplantation from expanded criteria donors," Journal of the American College of Surgeons, vol. 204, no. 5, pp. 873-882, 2007.

[51] J. A. Van Der Vliet and M. C. Warlé, "The need to reduce cold ischemia time in kidney transplantation," Current Opinion in Organ Transplantation, vol. 18, no. 2, pp. 174-178, 2013.

[52] J. Gill, J. Dong, M. Eng, D. Landsberg, and J. S. Gill, "Pulsatile perfusion reduces the risk of delayed graft function in deceased donor kidney transplants, irrespective of donor type and cold ischemic time," Transplantation, vol. 97, no. 6, pp. 668-674, 2014. 
[53] A. Asderakis, P. Dyer, T. Augustine, J. Worthington, B. Campbell, and R. W. G. Johnson, "Effect of cold ischemic time and hla matching in kidneys coming from "young" and "old" donors: do not leave for tomorrow what you can do tonight," Transplantation, vol. 72, no. 4, pp. 674-678, 2001.

[54] C. Troppmann, K. J. Gillingham, E. Benedetti et al., "Delayed graft function, acute rejection, and outcome after cadaver renal transplantation: a multivariate analysis," Transplantation, vol. 59, no. 7, pp. 962-968, 1995. 


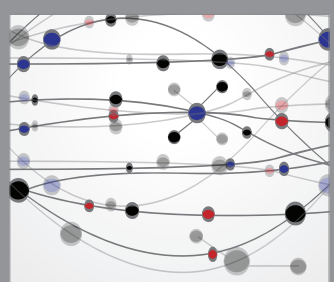

The Scientific World Journal
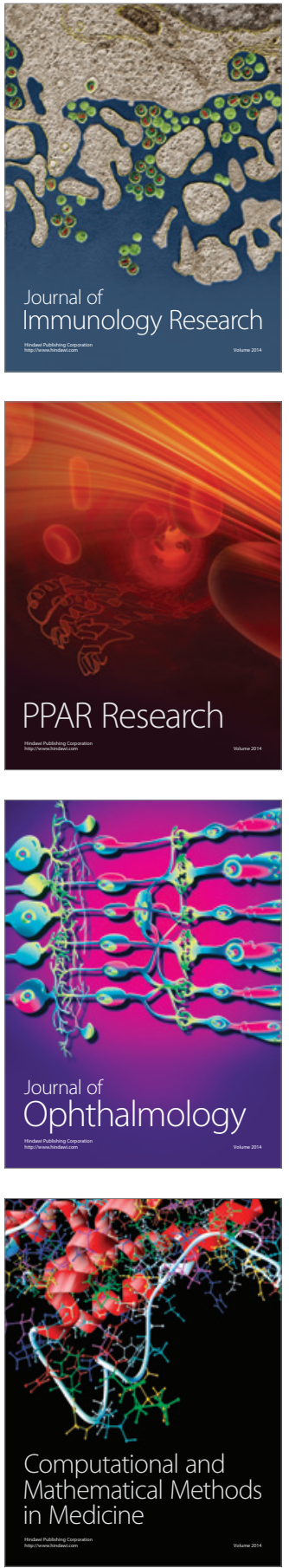

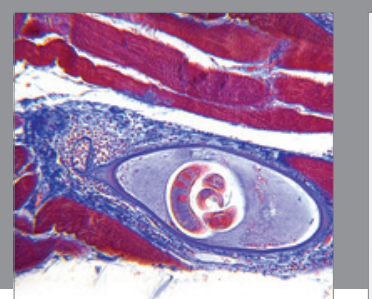

Gastroenterology Research and Practice
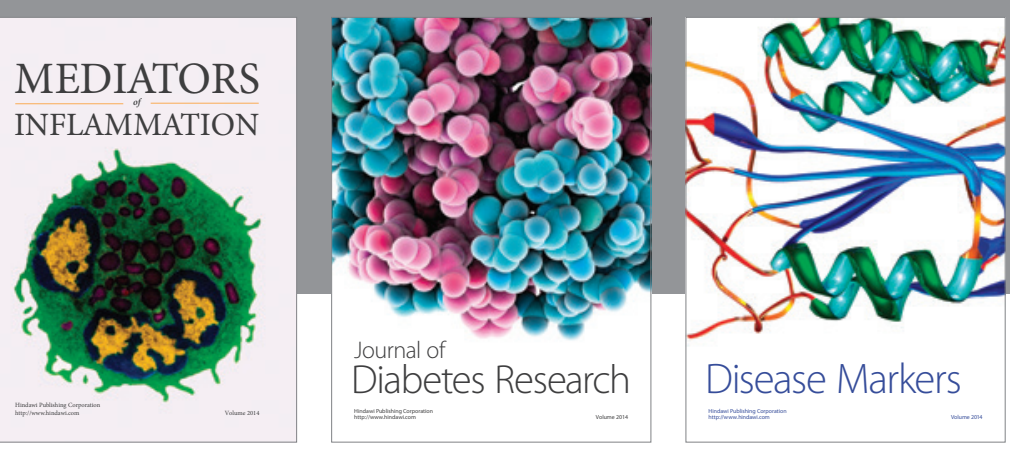

Disease Markers

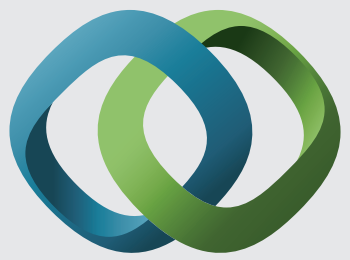

\section{Hindawi}

Submit your manuscripts at

https://www.hindawi.com
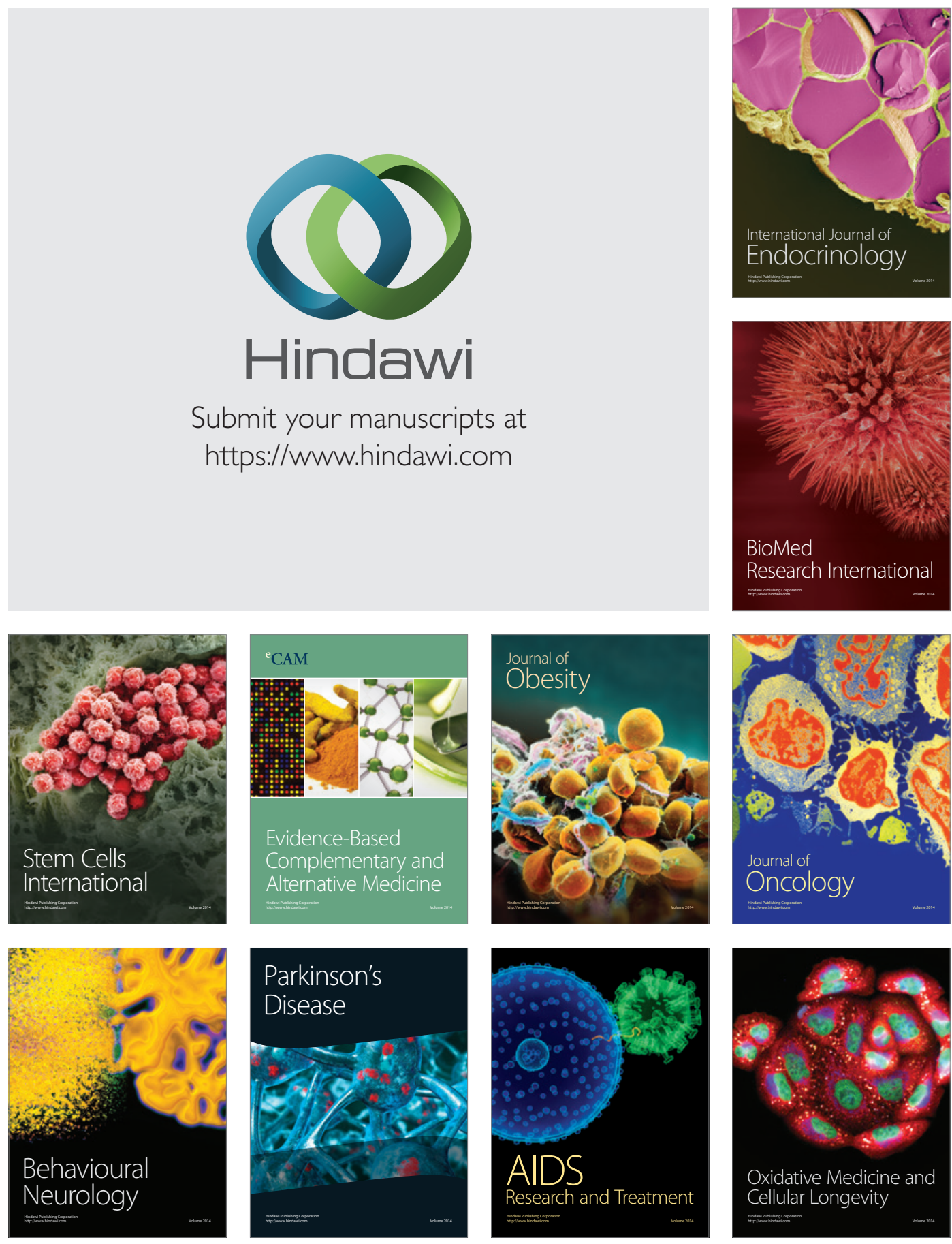